\title{
Level of Stress, Predisposing Factors and Status of Mental Health among Pharmacy Students of a Private University of Dhaka, Bangladesh: A Cross Sectional Study
}

\author{
A. H. M. Nazmul Hasan* (D), Md. Anzam Ul Islam, Smaranika Rahman, Zobaida Mostarin Nishi, \\ Md. Jakir Hossain, Md. Zobayer Hossain Gorapi, Farhan Jamil, Md. Abu Sufian, Zabun Nahar, \\ Kanij Nahar Deepa, Md. Hamiduzzaman, Md. Asaduzzaman, Mohiuddin Ahmed Bhuiyan
}

Department of Pharmacy, University of Asia Pacific, Dhaka, Bangladesh

Email: *nazmul_0155@yahoo.com

How to cite this paper: Nazmul Hasan, A.H.M., Ul Islam, Md.A., Rahman, S., Nishi, Z.M., Hossain, Md.J., Gorapi, Md.Z.H., Jamil, F., Sufian, Md.A., Nahar, Z., Deepa, K.N., Hamiduzzaman, Md., Asaduzzaman, Md. and Bhuiyan, M.A. (2019) Level of Stress, Predisposing Factors and Status of Mental Health among Pharmacy Students of a Private University of Dhaka, Bangladesh: A Cross Sectional Study. Health, 11, 222-232.

https://doi.org/10.4236/health.2019.112020

Received: January 12, 2019

Accepted: February 23, 2019

Published: February 26, 2019

Copyright $\odot 2019$ by author(s) and Scientific Research Publishing Inc. This work is licensed under the Creative Commons Attribution International License (CC BY 4.0).

http://creativecommons.org/licenses/by/4.0/ (c) (i) Open Access

\begin{abstract}
Stress during tertiary educational period has significant negative effect on the performance of a student. Mental distress is increasing among students and is one of the important public health concerns. This study was carried out to investigate the socio demographic characteristics of students, level of their stress feeling, and status of mental health and to find out the co-relation of different factors associated with the level of stress feelings. A cross sectional study was conducted among the students of the Department of Pharmacy of UAP. A total of 504 students (181 male students and 323 female students) participated in this study. Feeling of severe stress was almost equal to both sexes. But, moderate level of stress was more associated with female students $(\mathrm{N}=253, \mathrm{~F}=78.33 \%)$ and overall female students were more stressful than male. Thought towards future career ranked one among many reasons of stress in students (59.67\% for male students and 37.46\% for female students). In terms of academic achievements, feeling of stress was higher in female students compared to male students $(34.98 \%$ for female students vs. $15.47 \%$ for male students). Other factors such as unrealistic expectations, family relationship and affairs, socio economic condition, being of too busy also significantly participate in the development of stress in young mind. Mental health status was estimated by considering some facts such as state of shock due to unwanted life events, lacking of expression of emotions, reduced feeling of pleasure, unusual thinking, fear of any specific objects, short term memory loss, self identity disorder and lack of self confidence. We co-related different risk factors like age, gender, socio-economic condition, unrealistic thought patter to different levels of stress feeling. Feelings of stress were most among
\end{abstract}


the student of 21 - 25 years of age. Socio-economic condition is always a great factor of stress, middle class society has more stress compared to other socio-economic classes. Psychological counseling is required in educational institution to detect and prevent mental distress and stress among students.

\section{Keywords}

Stress, Factors of Stress, Mental Health

\section{Introduction}

Mental distress is a public health concern including anxiety, stress and depression having symptoms like sleep disorder, headache, loss of appetite, irritating behavior and detached from social life and frequently requires counseling and medical attention [1]. Mental health may be defined as the successful execution of mental function in terms of conception, mood and behavior which generates productive activities, maintenance of relationship within social context and the ability to adapt with time course [2]. The term stress has different meanings to different people depending on circumstances. Stress may be defined as the non specific response of the body to any demand. According to behavioral sciences, stress is regarded as the perception of threat with resulting anxiety, emotional tension and difficulty in adjustment [3]. On the other hand, anxiety is a kind of response of the body to a perceived threat that is triggered by personal beliefs, feelings and thoughts and is characterized by a number of symptoms like worried thoughts, increased blood pressure and pulse, sweating, chest pain, etc. Manifestations of depression include loss of interest or pleasure, sadness, felling of guilt, sleeplessness, loss of appetite and poor concentration and can also affect the outcome of many chronic diseases, e.g. diabetes, cardiovascular disease and obesity [4].

According to WHO, mental health disorders are one of the leading causes of disability worldwide. It is reported that three of ten leading causes of disability in people between the ages of 15 to 44 are mental disorders [5]. Stressful events during educational period have significant negative influence on academic, professional, personal and social life [4] [6]. It is already proved in many research articles that mental health problems among students are increasing every year and students of higher education institutions are experiencing serious mental health problems at a greater rate than their peers who are not student [7]. Studies on mental health/stress in our society/country are inadequate. This study is the first of its kind in our country to find out stress level and associated factors involved in stress development among university students.

\section{Methods}

\subsection{Study Design}

This research was conducted as a cross sectional study among sufficient number 
of students of the Department of Pharmacy of University of Asia Pacific, Dhaka, Bangladesh. This study was conducted in the month of May, 2018, when there was no exam, so stress related to exam was eliminated. The aim of this study was to investigate the demographic characteristics, level of feeling of stress, predisposing factors of their feeling of stress and their significance. Determination of the level of stress was based on individual feelings towards different stressors and modified DASS (Depression, Anxiety and Stress Scale) was used to estimate the level of stress [5] [6].

\subsection{Study Tools}

This study was conducted with a predesigned questionnaire to know the demographic data, socio economic condition and life style of the respondents. Informed consent was obtained from the respondents and no one was forced to participate in this study. Statistical analysis was done by SPSS-12 and Microsoft Excel [5] [6].

\subsection{Study Population}

Total 504 students were participated of both Bachelor and Masters Level voluntarily. All the students studying in the department were invited to participate in the study and among those 504 students of different level of Bachelor and Masters Program gave consent to participate in the study.

\subsection{Ethical Consideration}

This study was approved by ethical committee

(Ref: UAP/Pharm_ETA:04_012018) of the Department of Pharmacy of University of Asia Pacific. Written consent was obtained from the respondents' prior filling of the questionnaire. Questionnaires obtained from individual respondents were given a code number and strictly preserved to protect the leak of any personal information.

\section{Results}

\subsection{Demographic Characteristics}

Table 1 shows the demographic distribution of the students participated in this study. A total of 504 students (Male: $\mathrm{N}=181, \% \mathrm{~F}=35.91 \%$ and Female: $\mathrm{N}=$ $323, \% \mathrm{~F}=64.09$ ) of different level of the university were involved in this study. Respondents were further classified in different age group and level of education. Socio economic class of the respondents was calculated by modified B.G. Prasad Socio-economic Scale for 2016 [8] [9]. Among the participants, $64.09 \%$ were female compared to male participant of $35.91 \%$. Frequency of female students studying in the department of Pharmacy of UAP is usually higher compared to male counterpart. After completing Higher Secondary Certificate Examination, students from different parts of the country comes to Dhaka to seek admission to 
Table 1. Demographic distribution of respondents.

\begin{tabular}{|c|c|c|c|c|}
\hline \multirow[t]{2}{*}{ Characteristics } & \multicolumn{2}{|c|}{ Male } & \multicolumn{2}{|c|}{ Female } \\
\hline & Number & Frequency & Number & Frequency \\
\hline Respondents & 181 & 35.91 & 323 & 64.09 \\
\hline \multicolumn{5}{|l|}{ Age } \\
\hline $17-20$ & 45 & 24.86 & 101 & 31.27 \\
\hline $21-25$ & 133 & 73.48 & 219 & 67.80 \\
\hline $26-30$ & 3 & 1.66 & 3 & 0.93 \\
\hline Average Age (mean $\pm S D)$ & $21.75 \pm 1.78$ & & $21.48 \pm 1.80$ & \\
\hline \multicolumn{5}{|l|}{ Religion } \\
\hline Muslim & 156 & 86.19 & 295 & 91.33 \\
\hline Hindu & 21 & 11.60 & 28 & 8.67 \\
\hline Christian & 3 & 1.66 & 0 & 0.00 \\
\hline Buddhist & 1 & 0.55 & 0 & 0.00 \\
\hline \multicolumn{5}{|l|}{ Marital Status } \\
\hline Single & 177 & 97.79 & 297 & 91.95 \\
\hline Married & 4 & 2.21 & 24 & 7.43 \\
\hline Divorced & 0 & 0.00 & 2 & 0.62 \\
\hline Widowed & 0 & 0.00 & 0 & 0.00 \\
\hline \multicolumn{5}{|l|}{ Level of Education } \\
\hline Bachelor Program & 168 & 92.82 & 287 & 88.85 \\
\hline 1st Year & 48 & 26.52 & 68 & 21.05 \\
\hline 2nd Year & 41 & 22.65 & 81 & 25.08 \\
\hline 3rd Year & 35 & 19.34 & 64 & 19.81 \\
\hline 4th Year & 44 & 24.31 & 74 & 22.91 \\
\hline Masters Program & 13 & 7.18 & 36 & 11.15 \\
\hline \multicolumn{5}{|l|}{ Residential Status } \\
\hline Living in Dhaka Metropolitan & 53 & 29.28 & 158 & 48.92 \\
\hline Migrated to Dhaka & 96 & 53.04 & 100 & 30.96 \\
\hline Nearby Dhaka Metropolitan & 32 & 17.68 & 65 & 20.12 \\
\hline \multicolumn{5}{|l|}{ Current Living Status } \\
\hline With Family & 78 & 43.09 & 213 & 65.94 \\
\hline Student Hostel & 103 & 56.91 & 110 & 34.06 \\
\hline \multicolumn{5}{|l|}{ Division } \\
\hline Dhaka & 96 & 53.04 & 196 & 60.68 \\
\hline Rajshahi & 24 & 13.26 & 53 & 16.41 \\
\hline Chittagong & 32 & 17.68 & 34 & 10.53 \\
\hline Khulna & 14 & 7.73 & 17 & 5.26 \\
\hline
\end{tabular}


Continued

\begin{tabular}{ccccc}
\hline Barisal & 4 & 2.21 & 6 & 1.86 \\
Sylhet & 2 & 1.10 & 1 & 0.31 \\
Rangpur & 8 & 4.42 & 15 & 4.64 \\
Mymensing & 1 & 0.55 & 1 & 0.31 \\
\hline Socio-Economic Class & & & & \\
\hline Upper Class & 4 & 2.21 & 15 & 8.29 \\
Upper Middle Class & 16 & 8.84 & 90 & 49.72 \\
Middle Class & 126 & 69.61 & 199 & 61.61 \\
Lower Middle Class & 25 & 13.81 & 15 & 8.29 \\
Poor & 10 & 5.52 & 4 & 2.21 \\
\hline History of Familial & & & & \\
\hline Psychological Disorder & & & & \\
\hline Yes & 13 & 7.18 & 41 & 12.69 \\
No & 168 & 92.82 & 282 & 87.31 \\
\hline Addiction & 118 & & & \\
\hline Smoking & 51 & 28.18 & 304 & 94.12 \\
Alcohol & 12 & 6.63 & 95.19 & \\
None & & & & \\
\hline
\end{tabular}

different universities of their choice, as evidenced by the frequency of students studying in this university were from outer parts of Dhaka $(\mathrm{N}=96,53.04 \%$ for male students, $\mathrm{N}=100,30.96 \%$ for female students), but number of migrated male students to Dhaka is higher compared to female students. Consequently, frequency of male student living in the hostel was higher $(\mathrm{N}=103, \% \mathrm{~F}=$ $56.91 \%)$ than of female students $(\mathrm{N}=100, \% \mathrm{~F}=30.96 \%)$. Highest number of students participated in this study were from middle class family. Frequency of smokers was found highest in male students.

\subsection{Level of Stress and Factors Participating behind Feeling of Stress}

In this study, severe stress were almost equal (although slightly higher in male) to both sex (Figure 1). But, feeling of moderate level of stress were more associated with female students $(\mathrm{N}=253, \mathrm{~F}=78.33 \%)$. According to this study, we found that feeling of stress were more associated with female students.

Feelings of stress are significantly associated with many factors. Pattern of thought varies extremely among male and female individual. Such distinctive type thought and fear towards future life strongly buildup stress in an individual. In this study, we determined the factors most participating to build up stress and summarized in Table 2.

According this study, students feel highest percentage of stress due to thought towards future career $(59.67 \%$ for male students and $37.46 \%$ for female students). In terms of academic achievements, feeling of stress is significantly 


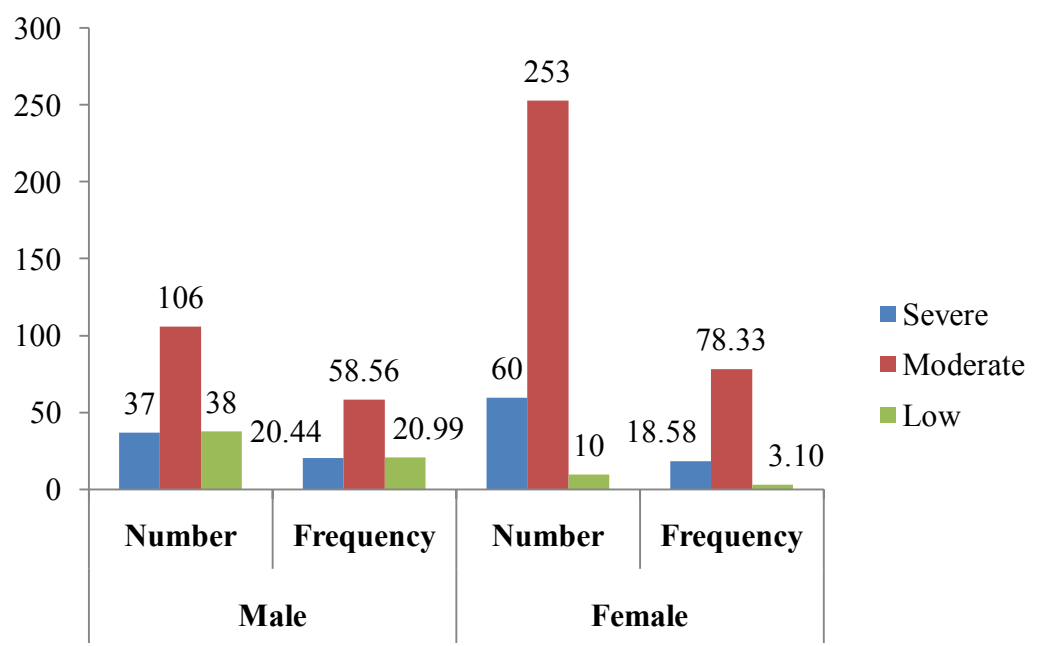

Figure 1. Feeling of level of stress of male and female students.

Table 2. Reasons of feeling stress in both sexes.

\begin{tabular}{ccccc}
\hline Factors & \multicolumn{3}{c}{ Male } & \multicolumn{2}{c}{ Female } \\
\hline & Number & Frequency & Number & Frequency \\
\hline Future Career & 108 & 59.67 & 121 & 37.46 \\
Academic Achievements & 28 & 15.47 & 113 & 34.98 \\
Unrealistic Expectation & 5 & 2.76 & 0 & 0.00 \\
Family Relationship and Affairs & 15 & 8.29 & 57 & 17.65 \\
Social Status & 4 & 2.21 & 15 & 4.64 \\
Being too Busy & 15 & 8.29 & 12 & 3.72 \\
Inability to Deal with Uncertainty & 4 & 2.21 & 5 & 1.55 \\
Lack of Flexibility & 2 & 1.10 & 0 & 0.00 \\
\hline
\end{tabular}

higher compared to male students $(34.98 \%$ for female students vs. $15.47 \%$ for male students). Other factors such as unrealistic expectations, family relationship and affairs, social status, being of too busy also significantly participate in the development of stress in young mind.

\subsection{Status of Mental Health}

Stress significantly affects the quality of life and mental health. Status of mental health and well being is estimated by considering some facts such as feeling of shocked by unwanted events in life, lacking of expression of emotions, reduced feeling of pleasure, unusual thinking, fear of any specific objects, short term memory loss, self identity disorder and lack of self confidence (Table 3). Prevalence of any specific facts of mental health was determined by the presence (Yes) or absence (No).

\subsection{Co-Relation of Different Risk Factors to Feeling of Different Level of Stress}

In our study, we co-related different risk factors like age, gender, socio-economic condition, unrealistic thought pattern to different level of stress feeling and 
Table 3. Factors affecting mental distress.

\begin{tabular}{|c|c|c|c|c|}
\hline \multirow[t]{2}{*}{ Factors } & \multicolumn{2}{|c|}{ Male } & \multicolumn{2}{|c|}{ Female } \\
\hline & Number & Frequency & Number & Frequency \\
\hline \multicolumn{5}{|c|}{ Shocked by Life Event } \\
\hline Yes & 113 & 62.43 & 202 & 62.54 \\
\hline No & 68 & 37.57 & 121 & 37.46 \\
\hline \multicolumn{5}{|c|}{ Lack of Expression of Emotion } \\
\hline Yes & 116 & 64.09 & 192 & 59.44 \\
\hline No & 65 & 35.91 & 131 & 40.56 \\
\hline \multicolumn{5}{|c|}{ Reduced Feeling of Pleasure } \\
\hline Yes & 97 & 53.59 & 156 & 48.30 \\
\hline No & 84 & 46.41 & 167 & 51.70 \\
\hline \multicolumn{5}{|c|}{ Unusual Thinking } \\
\hline Yes & 86 & 47.51 & 132 & 40.87 \\
\hline No & 95 & 52.49 & 191 & 59.13 \\
\hline \multicolumn{5}{|c|}{ Fear of Any Specific Thing/Object } \\
\hline Yes & 80 & 44.20 & 207 & 64.09 \\
\hline No & 101 & 55.80 & 116 & 35.91 \\
\hline \multicolumn{5}{|c|}{ Self Identity Disorder } \\
\hline Yes & 61 & 33.70 & 141 & 43.65 \\
\hline No & 120 & 66.30 & 182 & 56.35 \\
\hline \multicolumn{5}{|c|}{ Short Term Memory Loss } \\
\hline Yes & 43 & 23.76 & 107 & 33.13 \\
\hline No & 138 & 76.24 & 216 & 66.87 \\
\hline \multicolumn{5}{|c|}{ Lack of Self Confidence } \\
\hline Yes & 159 & 87.85 & 257 & 79.57 \\
\hline No & 22 & 12.15 & 66 & 20.43 \\
\hline \multicolumn{5}{|c|}{ Sharing of Feelings with Parents } \\
\hline Yes & 108 & 59.67 & 165 & 51.08 \\
\hline No & 73 & 40.33 & 158 & 48.92 \\
\hline \multicolumn{5}{|c|}{ Sharing of Feelings with Siblings } \\
\hline Yes & 99 & 54.70 & 171 & 52.94 \\
\hline No & 82 & 45.30 & 152 & 47.06 \\
\hline \multicolumn{5}{|c|}{ Sharing of Feelings with Friends } \\
\hline Yes & 147 & 81.22 & 213 & 65.94 \\
\hline No & 34 & 18.78 & 110 & 34.06 \\
\hline \multirow[t]{2}{*}{ Factors } & \multicolumn{2}{|c|}{ Male } & \multicolumn{2}{|c|}{ Female } \\
\hline & Number & Frequency & Number & Frequency \\
\hline \multicolumn{5}{|c|}{ Feelings of Upset } \\
\hline Never & 21 & 11.60 & 18 & 5.57 \\
\hline Sometimes & 113 & 62.43 & 199 & 61.61 \\
\hline
\end{tabular}


Continued

\begin{tabular}{ccccc}
\hline Fairly Often & 24 & 13.26 & 47 & 14.55 \\
Very Often & 23 & 12.71 & 59 & 18.27 \\
\hline Feelings of Anger & & & & \\
\hline Never & 28 & 15.47 & 25 & 7.74 \\
Sometimes & 106 & 58.56 & 168 & 52.01 \\
Fairly Often & 26 & 14.36 & 52 & 16.10 \\
Very Often & 21 & 11.60 & 78 & 24.15 \\
\hline Level of Satisfaction & & & & \\
\hline Not Satisfied & 30 & 16.57 & 30 & 9.29 \\
Moderately Satisfied & 87 & 48.07 & 183 & 56.66 \\
Satisfied & 64 & 35.36 & 110 & 34.06 \\
\hline
\end{tabular}

results are summarized in the following table (Table 4). Feelings of stress are most among the student of 21 - 25 years of age. According to this study, female students were more stressed compared to male counterparts. Socio-economic condition is always a great factor of stress and in our study, middle class society had more stress compared to other socio-economic class.

\section{Discussion}

Globally, among many psychiatric health problems, psychological morbidities are most common and mental health among university students is, now a day's an important and developing public health concern [10]. Stress among university students arise from both academic and non-academic factors, also including socio-economic and cultural, environmental and psychological attributes [11]. Gender also significantly contributes to the level of stress felling. In our study, analysis of level of stress feeling come out with some interesting data. According to this study, feeling of severe level of stress is almost equal in both sex (20.44\% for male Vs $18.58 \%$ for female), but female students felt highest percent of moderate level of stress $(78.33 \%)$ compared to male $(58.56 \%)$. The levels of stress are different among students and also different among male and female students [12]. It is already revealed in many literatures that students of health sciences undergo tremendous stress during various level of their education [13] [14]. There have been several key factors identified as a potential stressor in university life [15]. According to our study, future career, academic achievements and family relationship and affairs are the top three reasons of feeling of stressed among students of both sex. In this present study, we also identified several key factors that significantly contribute to mental distress. It is really a matter of worried and observable that now a day in modern context of life style, there is a significant reduction in the sharing of feelings or emotions, reduce in the feeling of pleasure, feeling of self identity disorder and not being satisfied in the context of life significantly contributing to mental distress among students. More over due to complexity in life and stress, major portion of students are not being satisfied 
Table 4. Risk factor analysis of stress.

\begin{tabular}{ccccc}
\hline Risk Factors & \multicolumn{2}{c}{ Level of Feeling of Stress } & \multirow{2}{*}{ Chi-Square/df } \\
\hline Age & Severe (N, \% F) & Moderate (N, \% F) & Low (N, \%F) & \\
\cline { 1 - 3 } $17-20$ & $30,5.95 \%$ & $105,20.83 \%$ & $11,2.18 \%$ & \multirow{2}{*}{$2.14 / 6$} \\
$21-25$ & $66,13.10 \%$ & $249,49.40 \%$ & $37,7.34 \%$ & \\
26 - 30 & $1,0.20 \%$ & $5,0.99 \%$ & $0,0 \%$ & \\
\hline Socio-Economic Class & & & & \\
\hline Upper Class & $4,0.79 \%$ & $13,2.58 \%$ & $2,0.40 \%$ & \\
Upper Middle Class & $20,3.97 \%$ & $79,15.67 \%$ & $7,1.39 \%$ & \\
Middle Class & $55,10.91 \%$ & $238,47.22 \%$ & $32,6.25 \%$ & \\
Lower Middle Class & $11,2.18 \%$ & $22,4.37 \%$ & $7,1.39 \%$ & \\
Poor & $7,1.39 \%$ & $7,1.39 \%$ & $0,0 \%$ & \\
\hline Unusual Thought & & & & \\
\hline Yes & $48,9.52 \%$ & $153,30.36 \%$ & $17,3.37 \%$ & \\
No & $48,9.52 \%$ & $207,41.07 \%$ & $31,6.15 \%$ & \\
\hline
\end{tabular}

about their life. Students in between the age of $21-25$ felt most stress as at this level when they are advancing towards their upper level of tertiary education, they always co-related their academic progress, their future career and many others. Level of feeling of stress is most in case of students from middle class. People of middle class society always face some kind of complexity to maintain their social status could be a reason of their higher stress feeling. University students usually face a kind of transition from adolescence to adulthood as stressful. At university level, students first start to take responsibility for their own decision and life style, career, recreational activities, health and many more. More over adaptation to new environment, new approach of learning, academic and social demands boost up stress in to student life [15] [16].

\section{Conclusion}

This study found that, students participated in this study had some level of stress, but feeling of stress was higher to female students compared of their opposite. According to this study, some important factors such as future career, academic achievement, certain socio demographic characteristics, personal feeling of satisfaction are significantly associated with feeling of stress. Psychological counseling should be an important part in our educational institution to detect and prevent mental distress among students. Moreover, students should be encouraged to seek help from other and share their feeling to reduce stress and more studies in this area are highly required.

\section{Acknowledgements}

Authors are thankful to the participants in this survey study and the Institute for Energy, Environment, Research and Development (IEERD), UAP for their approval in this research work. 


\section{Conflicts of Interest}

The authors declared no conflict of interest in connection with this research, authorship and/or publication of this article.

\section{References}

[1] Dachew, B.A., Bisetegn, T.A. and Gebremariam, R.B. (2015) Prevalence of Mental Distress and Associated Factors among Undergraduate Students of University of Gondar, Northwest Ethiopia: Across Sectional Institutional Based Study. PLoS $O N E, 10,1-10$. https://doi.org/10.1371/journal.pone.0119464

[2] Hersi, L., Tesfay, K., Gesesew, H., Krahl, W., Ereg, D. and Tesfaye, M. (2017) Mental Distress and Associated Factors among Undergraduate Students at the University of Hargeisa, Somaliland: A Cross-Sectional Study. International Journal of Mental Health Systems, 11, 2-8. https://doi.org/10.1186/s13033-017-0146-2

[3] Fink, G. (2017) Stress: Concepts, Definition and History. In Reference Module Inneuroscience and Biobehavioral Psychology, Elsevier Inc., Amsterdam, 1-9. https://doi.org/10.1016/B978-0-12-809324-5.02208-2

[4] Yeshaw, Y. and Mossie, A. (2017) Depression, Anxiety, Stress, and Their Associated Factors among Jimma University Staff, Jimma, Southwest Ethiopia, 2016: A Cross-Sectional Study. Neuropsychiatric Disease and Treatment, 13, 2803-2812. https://doi.org/10.2147/NDT.S150444

[5] Wahed, W.A. and Hassan, S.K. (2017) Prevalence and Associated Factors of Stress, Anxiety and Depression among Medical Fayoum University Students. Alexandria Journal of Medicine, 53, 77-84. https://doi.org/10.1016/j.ajme.2016.01.005

[6] Jovanović, V.R., Đonović, N. and Dutina, A. (2017) Factors Associated with the Depression, Anxiety and Stress among High Medical School of Professional Studies Students. Medicinski Časopis, 51, 7-14. https://doi.org/10.5937/mckg51-14379

[7] Lee, M.F. and Syaid, S. (2017) Factors Contributing towards Malaysian Technical University (MTU) Students' Mental Health. Pertanika Journal of Social Sciences \& Humanities, 25, 93-100.

[8] Tabassum, N. and Rao, R.L. (2017) An Update on B.G. Prasad's Socio Economic Classification. JMPAS, 6, 670-673.

[9] Vasudevan, J., Mishra, A.K. and Singh, Z. (2016) An Update on B.G. Prasad's Socio Economic Scale: May 2016. International Journal of Research in Medical Sciences, 4, 4183-4186. https://doi.org/10.18203/2320-6012.ijrms20162957

[10] Syed, A. and Ali, S.S. (2018) Frequency of Depression, Anxiety and Stress among the Undergraduate Physiotherapy Students. Pakistan Journal of Medical Science, 34, 468-471. https://doi.org/10.12669/pjms.342.12298

[11] Bedewy, D. and Gabriel, A. (2015) Examining Perceptions of Academic Stress and Its Sources among University Students: The Perception of Academic Stress Scale. Health Psychology Open, 2, 1-9. https://doi.org/10.1177/2055102915596714

[12] Mazumdar, H., Gogoi, D., Buragohain, L. and Haloi, N. (2012) A Comparative Study on Stress and Its Contributing Factors among the Graduate and Post-Graduate Students. Advances in Applied Science Research, 3, 399-406.

[13] Rahman, A.A., Al-Hashim, B.N., Al-Hiji, N.K. and Al-Abbad, Z. (2012) Stress among Medical Saudi Students at College of Medicine, King Faisal University. Journal of Preventive Medicine and Hygiene, 54, 195-199.

[14] Abdulghani, H.M., AlKanhal, A.A., Mahmoud, E.S., Ponnamperuma, G.G. and Al- 
faris, E.A. (2011) Stress and Its Effects on Medical Students: A Cross-Sectional Study at a College of Medicine in Saudi Arabia. Journal of Health, Population and Nutrition, 29, 516-522. https://doi.org/10.3329/jhpn.v29i5.8906

[15] Lee, P.C., Ahmed, F., Pathirana, T. and Papier, K. (2016) Factors Associated with Stress among First-Year Undergraduate Students Attending an Australian University. FNR, 1, 17-24.

[16] Cheung, T., Wong, S.Y., Wong, K.Y., Law, L.Y., Ng, K., Tong, M.T., et al. (2016) Depression, Anxiety and Symptoms of Stress among Baccalaureate Nursing Students in Hong Kong: A Cross-Sectional Study. International Journal of Environmental Research and Public Health, 13, 2-25.

https://doi.org/10.3390/ijerph13080779 